\title{
Colorectal Neuroendocrine Tumor pT1 TNM Finding v8
}

National Cancer Institute

\section{Source}

National Cancer Institute. Colorectal Neuroendocrine Tumor pT1 TNM Finding v8. NCI

Thesaurus. Code C135186.

Colorectal neuroendocrine tumor invading the lamina propria or submucosa and measuring $2 \mathrm{~cm}$ or less. (from AJCC 8th Ed.) 